\title{
Effects of Concentration of Triethanolamine and Annealing Temperature on Band Gap of Thin Film of Tin Sulphide Prepared by Chemical Bath Deposition Method
}

\author{
Leela Pradhan Joshi ${ }^{1}$, Laxmi Risal ${ }^{2}$, Shankar Prasad Shrestha ${ }^{2}$ \\ ${ }^{1}$ Department of Physics, Amrit Science Campus, Tribhuvan University, Kathmandu, Nepal \\ ${ }^{2}$ Department of Physics, Patan Multiple Campus, Tribhuvan University, Kathmandu, Nepal \\ Corresponding author: Leela Pradhan (leela.pradhan@gmail.com)
}

\begin{abstract}
Thin films of Tin Sulphide (SnS) were deposited by chemical bath deposition technique using a precursor solution of stannous chloride $\left(\mathrm{SnCl}_{2} \cdot 2 \mathrm{H}_{2} \mathrm{O}\right)$, thioacetamide (TA), triethanolamine (TEA), ammonia $\left(\mathrm{NH}_{3}\right)$, and distilled water. The effects of concentration of triethanolamine and annealing temperature on the growth of SnS films were studied to optimize the growth conditions. X-ray diffraction study shows the deposited films were polycrystalline in nature and orthorhombic in structure. The optical direct and indirect band gap values of SnS films prepared with $15 \mathrm{ml}$ of TEA were found to be $1.76 \mathrm{eV}$ and $0.89 \mathrm{eV}$ respectively. Annealing the sample prepared with $12 \mathrm{ml}$ of TEA results increase in band gap from $1.79 \mathrm{eV}$ to $3.32 \mathrm{eV}$.
\end{abstract}

Keywords: Thin films, optical band gap, photovoltaic materials, X-ray diffraction

\section{Introduction}

In recent years, semiconducting thin films of nano-materials have been attracting a lot of attention due to their unique physical and chemical properties which help to enhance device performance [Anuar et al., 2008] Polycrystalline thin films of tin sulphide $(\mathrm{SnS})$ are considered as a potential material for solar cells because of their photovoltaic properties. Tin sulphide is a cost-effective and environmentally friendly material among the group of compound semiconductors that are currently being explored for low-cost photovoltaic materials. It possesses a high optical absorption coefficient which is greater than $10^{4} \mathrm{~cm}^{-1}$ [Ristov et al., 1989]. The physical and optical properties of $\mathrm{SnS}$ such as its color and optical band gap depend on the method employed to prepare it. There are numerous methods of preparing thin films of metal oxide and sulphide materials such as spray pyrolysis [Jeyaprakash et al., 2010], atomic layer deposition [Kim and Steven, 2010], successive ionic layer adsorption and reaction [Ghosh et al., 2008], and chemical bath deposition [Nair and Nair, 1991]. However, during the deposition process, many other related phases are likely to form: $\mathrm{SnS}_{2}$. $\mathrm{Sn}_{2} \mathrm{~S}_{3}$ and $\mathrm{Sn}_{3} \mathrm{~S}_{4}$ [Calixto-Rodriguez et al., 2009]. The chemical bath deposition method is an economic and efficient method for preparing thin films of $\mathrm{SnS}$. This method 
does not require vacuum conditions and hence is appropriate for basic research [Ristov et al., 1989]. In this work, we have prepared thin films of $\mathrm{SnS}$ using this method and investigated the influence of concentration of TEA in the precursor solution and the annealing temperature towards the optical energy band gap measurement of the films on glass substrate. The structure of the film was studied by using X-ray diffraction technique. The optical absorption properties were determined by using a UV-Visible Spectrophotometer.

\section{Experimental}

Thin films of SnS were deposited using a chemical bath deposition at room temperature. The precursor solution was prepared by mixing equal volumes of $0.1 \mathrm{M}$ stannous chloride, $\left(\mathrm{SnCl}_{2} \cdot 2 \mathrm{H}_{2} \mathrm{O}\right)$ and $0.1 \mathrm{M}$ thioacetamide (TA), $15 \mathrm{ml}$ of Triethanolamine (TEA) and $8 \mathrm{ml}$ of ammonia $\left(25 \% \mathrm{NH}_{3}\right)$ and distilled water [Pramanik et al., 1987] . All the chemicals used were of analytical grade. Ultrasonically cleaned glass substrates were vertically dipped into the as-prepared bath solution at room temperature $\left(26^{\circ} \mathrm{C}\right)$ for 22 hours. Then, the substrates were taken out, rinsed with distilled water and dried in air. The structural properties of the as-prepared films were studied using a Rigaku diffractometer with $\mathrm{CuK}_{\alpha}$ radiation of wavelength, $\lambda=1.54056$ Angstrom $(\AA)$. The optical transmittances ( $\mathrm{T} \%$ ) of the deposited thin films were measured with an Ocean Optics USB 2000 Spectrophotometer, Singapore. This transmittance data was utilized to plot $(\alpha \mathrm{h} v)^{2}$ versus $h v$ and $(\alpha h v)^{1 / 2}$ versus $h v$ and hence calculated the direct and indirect optical band gap $\left(\mathrm{E}_{\mathrm{g}}\right)$ of $\mathrm{SnS}$ thin films [Jeyaprakash et al., 2009].

\section{Results and Discussions}

The deposited thin films were uniform and dark brown in color. Figure 1 depicts the $\mathrm{X}$-ray diffraction pattern of the as-prepared thin film. Three major peaks were observed at $2 \theta=26.6116^{\circ}, 30.7920^{\circ}$, and $44.0935^{\circ}$ respectively. Table 1 shows the corresponding $\mathrm{d}$-spacing values and (hkl) plane orientation with reference to JCPDS card no. 83-1758 [Ghosh et al., 2008]. It shows that the peak at $2 \theta=26.6116^{\circ}$ corresponding to $d=3.3469 \AA$ of (021) orientation, $2 \theta=30.7920^{\circ}$ corresponding to $\mathrm{d}=2.9014 \AA$ of $(040)$ orientation, and $2 \theta$ $=44.0935^{\circ}$ corresponding to $\mathrm{d}=2.0521 \AA$ of (200) orientation. The result confirms that the deposited material was $\mathrm{SnS}$ film of polycrystalline and orthorhombic in structure. The crystallite size (D) of the $\mathrm{SnS}$ film was calculated using Debye Scherrer's formula, $\mathrm{D}=0.9 \lambda / \beta \cos \theta$ where $\lambda$ is the wavelength of $\mathrm{X}$-ray used and $\beta$ is full width half maximum

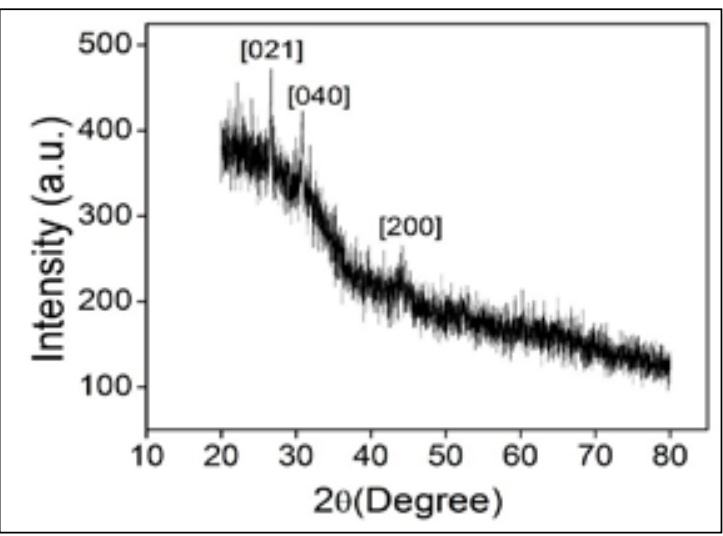

Figure 1. X-ray diffraction pattern of SnS film prepared at room temperature. 
(FWHM) measured in radian and $\theta$ is the Bragg angle [Guneria et al., 2010 ]. The average value of crystallite size of $\mathrm{SnS}$ film was found to be $320 \AA$.

Figure 2(a) shows the transmittance curves of SnS films prepared with different concentrations of TEA at room temperature captured in the wavelength range 400-1300 $\mathrm{nm}$. The maximum transmittance of about $60 \%$ above the fundamental edges was observed with $6 \mathrm{ml}$ of TEA. As the concentration of TEA decreased the transmittance was found to be increasing for the studied range of samples, it may be due to presence of higher band gap phase in the film. To determine the energy gap values, we plotted the graphs of $(\alpha h v)^{2}$ versus $h v$ and $(\alpha h v)^{1 / 2}$ versus $h v$ which was shown in Figure $2 \mathrm{~b}$ and Figure $2 \mathrm{c}$ respectively. The band energies were determined by extrapolating the straight line portion of the plots to intersect the hv axis [Jeyaprakash et al., 2009]. The direct and indirect energy band gaps for samples

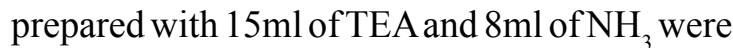
found to be $1.76 \mathrm{eV}$ and $0.89 \mathrm{eV}$ respectively. Figure $2 b$ showed the variation of direct band gap energy with TEA concentration. It was increased from $1.76 \mathrm{eV}$ to $2.11 \mathrm{eV}$ when we decreased the concentration of TEA from $15 \mathrm{ml}$ to $6 \mathrm{ml}$. Following the same trend, Figure $2 \mathrm{c}$ showed that the indirect energy gap increased from $0.89 \mathrm{eV}$ to $1.38 \mathrm{eV}$ for the same decrease of TEA concentration from $15 \mathrm{ml}$ to $6 \mathrm{ml}$. Figure $2 \mathrm{~d}$ shows the variation of $(\alpha \mathrm{h} v)^{2}$ with photon energy hv and observed energy values when the sample prepared with $12 \mathrm{ml}$ of TEA was heated from room temperature to $400^{\circ} \mathrm{C}$. The band gaps were found to be $1.79 \mathrm{eV}, 2.00 \mathrm{eV}$, $2.30 \mathrm{eV}$, and $3.32 \mathrm{eV}$ at $\mathrm{RT}, 200^{\circ} \mathrm{C}, 300^{\circ} \mathrm{C}$, and $400^{\circ} \mathrm{C}$ respectively. Annealing the film at high temperatures possibly changes their phases from SnS to binary sulfides: $\mathrm{SnS}_{2}$ or $\mathrm{Sn}_{2} \mathrm{~S}_{3}, \mathrm{Sn}_{3} \mathrm{~S}_{4}$, and $\mathrm{SnO}_{2}$ [Guneria et al., 2010]. The inset shows the direct band gap of $3.32 \mathrm{eV}$ measured at $400^{\circ} \mathrm{C}$. In the figures $2 \mathrm{a}$ through $2 \mathrm{c}$ the symbols: black filled squares, red filled circles, green filled up triangles, blue filled down triangles represent the $\mathrm{SnS}$ films prepared with $15 \mathrm{ml}, 12 \mathrm{ml}, 10 \mathrm{ml}$, and $6 \mathrm{ml}$ of TEA respectively. In figure $2 \mathrm{~d}$, the symbols: black filled squares, red filled circles, blue filled up triangles, dark cyan filled down triangles represent the $\mathrm{SnS}$ film prepared with $12 \mathrm{ml}$ of TEA but annealed at room temperature, $200^{\circ} \mathrm{C}, 300^{\circ} \mathrm{C}$, and $400^{\circ} \mathrm{C}$ respectively.

\section{Conclusions}

Thin films of tin sulphide were deposited on glass substrate at room temperature using chemical bath deposition. The X-ray analysis confirmed that the deposited material was $\mathrm{SnS}$ with polycrystalline and orthorhombic structure.

Table 1. 2 $\theta$, observed and JCPDS d-spacing, (hkl) values, FWHM, and grain size of SnS film

\begin{tabular}{|c|c|c|c|c|c|c|c|}
\hline S. N. & $\begin{array}{c}2 \theta \\
\text { ( Deg) }\end{array}$ & $\begin{array}{c}\text { Observed } \\
\text { d-spacing } \\
\text { (Á) }\end{array}$ & 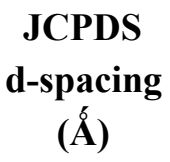 & (hkl) & $\begin{array}{c}\text { FWHM } \\
\text { in } \\
\text { degree }\end{array}$ & $\begin{array}{c}\text { Grain } \\
\text { Size } \\
\text { D(Á) }\end{array}$ & $\begin{array}{l}\text { JCPDS } \\
\text { File No. }\end{array}$ \\
\hline 1. & 26.6116 & 3.3469 & 3.3774 & (021) & 0.2574 & 317 & \multirow{3}{*}{$83-1758$} \\
\hline 2. & 30.7920 & 2.9014 & 2.8707 & (040) & 0.1608 & 512 & \\
\hline 3. & 44.0935 & 2.0521 & 2.0740 & (200) & 0.6494 & 132 & \\
\hline
\end{tabular}



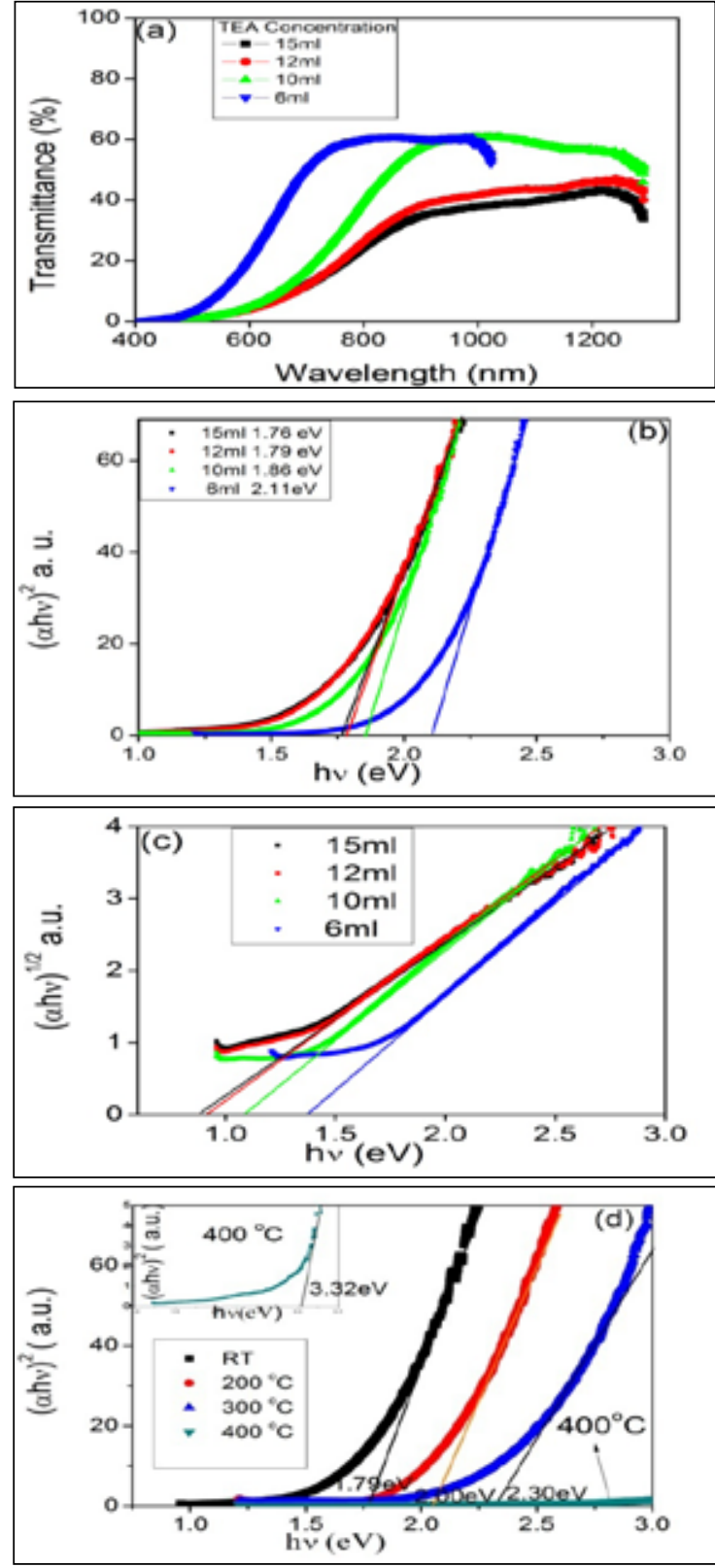

Figure 2. (a) Transmittance, $T \%$ versus wavelength (b) Plot of $(\alpha h v)^{2}$ versus hv (c) Plot of $(\alpha h v)^{1 / 2}$ versus hv for samples prepared with different concentration of TEA (d) variation of direct band gap with temperature for sample prepared with $12 \mathrm{ml}$ of TEA in the parent solution, inset to the figure shows plot for the sample annealed at $400^{\circ} \mathrm{C}$.

The average crystallite size of $\mathrm{SnS}$ was found to be $320 \AA$. The direct and indirect energy gap of as-prepared $\mathrm{SnS}$ film prepared with $15 \mathrm{ml}$ of TEA and $8 \mathrm{ml}$ of $\mathrm{NH}_{3}$ at room temperature were found to be $1.76 \mathrm{eV}$ and $0.89 \mathrm{eV}$ respectively. The effect of TEA concentration on band gap measurement concluded that the direct and indirect band gap increased with the decrease in concentration of TEA. Annealing the sample showed that increase in direct band gap values from $1.79 \mathrm{eV}$ to $3.32 \mathrm{eV}$ for the rise of temperature from room temperature to $400^{\circ} \mathrm{C}$, which may be due to change of phase from a mixture of $\mathrm{SnS}-\mathrm{SnS}_{2}$ to $\mathrm{SnS}-\mathrm{SnO}_{2}$ [CalixtoRodriguez et al., 2009].

\section{Acknowledgment}

Authors would like to thank Government of Nepal, Ministry of Science and Technology, Singh Durbar, Kathmandu, Nepal for providing financial support for this project. Editor N. P. Chapagain thanks referees for their help in evaluating this paper

\section{References}

Anuar, K., S. M. Ho, W. T. Tan, S. Atan, Z. Kuang, M. J. Haron, and N. Saravana (2008), Effects of Bath Temperature on the Electrodeposition of $\mathrm{Cu}_{4} \mathrm{SnS}$ Thin Films, Journal of Applied Sciences Research, 4, 1701-1707.

Calixto-Rodriguez, M., H. Martinez, A. SanchezJuarez, J. Campos-Alvarez, A. Tiburcio-Silver, M. E. Calixto (2009), Structural, optical, and electrical properties of tin sulfide thin films grown by spray pyrolysis, Thin Solid Films, 517, 2497-2499.

Ghosh B., M. Das, P. Banerjee, and S. Das (2008), Fabrication and optical properties of $\mathrm{SnS}$ thin films by SILAR method Applied Surface Science 254, 6436-6440.

Effects of Concentration of Triethanolamine 
Guneria E., F. Godec, C. Ulutasb, F. Kirmizigulb, G. Altindemirb, C. Gumusb (2010), Properties of P-type SnS Thin Films Prepared by Chemical Bath Deposition, Chalcogenide Letters, Vol. 7, 685-694.

Jeyaprakash, B. G., R. Ashok kumar, K.Kesavan, and A. Amalarani (2010), Structural and Optical Characterization of Spray Deposited SnS Thin Film, Journal of American Science, 6, 22-26.

Jeyaprakash, B.G., A. Amalarani, K. Kesavan, and S. Mohan (2009), Characterization of Microwave assisted chemically deposited SnS Thin Film, Chalcogenide Letters, 6, 455- 461.

Kim J. Y., and M. G. Steven (2010), Tin Monosulfide Thin Films Grown by Atomic Layer Deposition
Using Tin 2,4-Pentanedionate and Hydrogen Sulfide, J. Phys. Chem. C, 114, 17597-17603.

Nair, M. T. S., and P. K. Nair (1991), Simplified Chemical Deposition Technique for good quality SnS thin films, Semicond. Sci. Technol. 6, 132-134.

Pramanik, P., P. K. Basu, and S. Biswas (1987), Preparation and characterization of chemically deposited tin (II) Sulphide Thin Films, Thin Solid Films, 150, 269-276.

Ristov, M., G. Sinandinovski, I. Grozdanov, and M. Mitreski (1989), Chemical deposition of Tin(II) Sulphide Thin Films, Thin Solid Films, 173, 53-58. 